\title{
HEALTH PRACTITIONER NOTIFICATION OF COMPETENCE CONCERNS: CAREER SUICIDE V PATIENT SAFETY?
}

\author{
Anita Miller*
}

This article examines the discretionary notification of competence concerns by health practitioners, through the lens of patient safety. The discretion, provided for in the Health Practitioners Competence Assurance Act 2003, is discussed alongside ethical obligations, factors that may inhibit raising concerns about substandard practice, and the arguments for and against mandatory reporting of incompetent practice. It concludes that the absence of a statutory obligation to notify such concerns creates a risk that problems will go unreported and that patients may be exposed to harm. Comprehensive research into the source of notifications, and practitioners understanding of the threshold for raising concerns, is recommended. It is also suggested that legislative change to require mandatory reporting in certain circumstances may need to be reconsidered.

\section{INTRODUCTION}

The Code of Health and Disability Services Consumers' Rights 1996 (Code of Rights) confirms that patients are entitled to health services that are provided with reasonable care and skill, and that comply with legal, professional, ethical and other standards. ${ }^{1}$ "Reasonable care and skill" signifies the need for competent practice; patients are entitled to trust that their health provider has the necessary skills to safely provide health services. Likewise, a patient can expect a practitioner to practise in a manner that adheres to all relevant ethical duties, whatever those duties might be. Health providers have a corresponding duty to uphold the rights set out in the Code of Rights. ${ }^{2}$

* Partner, Claro, Wellington. Submitted as part of the LLM programme at Victoria University of Wellington. The author would like to thank Professor Bill Atkin for his advice and guidance during the development of this article.

1 Code of Health and Disability Services Consumers' Rights 1996 [Code of Rights], rights 4(1) and 4(2). The Code of Rights is a regulation promulgated under the Health and Disability Commissioner Act 1994.

2 Clause 1(2) 
With these patient rights and provider duties in mind, the focus of this paper is on the regulatory framework established by the Health Practitioners Competence Assurance Act 2003 (the Act) and, in particular, the existence of a discretionary notification regime for health practitioners to report concerns about incompetent colleagues. This paper discusses how the Act came about, how it seeks to assure practitioner competence, the process for notification of competence concerns and the reasons why discretionary notification was adopted for practitioners.

Using a patient-centric approach, it then questions whether discretionary notification is appropriate to ensure that the health and safety of the public is protected and whether ethical obligations act to address any possible deficiencies. It is suggested that professional and workplace pressures and concerns about career advancement may act to prevent health practitioners from exercising their discretion to notify, creating a risk that incompetent practice will go unreported and expose patients to harm. It is also argued that unless ethical obligations are consistent across the regulated professions and are enforced by relevant agencies they will not provide an effective backstop to discretionary notification. Options for improvement or change are then canvassed, including the need for New Zealand-based research into practitioner reporting behaviour and education and consistent guidance on the discretionary reporting threshold. Finally, it is proposed that, subject to research findings and the effect (if any) of suggested improvements, mandatory reporting may need to be reconsidered, and a proposal for amendments to the current statutory regime is set out and discussed.

\section{THE HEALTH PRACTITIONERS COMPETENCE ASSURANCE ACT 2003}

The Act, which came into force in September 2003, replaced 11 disparate, inflexible and outdated pieces of legislation that were considered unable to meet the changing needs of the health sector. ${ }^{3}$ However, the real impetus for legislative change came from a number of "high profile medical scandals" that created significant public disquiet about professional self-regulation. ${ }^{4}$

\section{A The Impetus for Change}

The 1988 Cartwright Inquiry ${ }^{5}$ into allegations about Dr Herbert Green's experimental research into cervical cancer at National Women's Hospital has been described as the "real beginning of New

3 Health Practitioners Competence Assurance Act 2003, sch 7. Some of the Acts replaced were over 50 years old, for example the Physiotherapy Act 1949.

4 Jonathan Coates "Mandatory Reporting of Incompetence" (2001) 114 NZ Med J 193

5 Silvia Cartwright The Report of the Cervical Cancer Inquiry (1988). The inquiry was prompted by a Metro magazine article: Sandra Coney and Phillida Bundle "An 'Unfortunate Experiment' at National Women's" Metro (New Zealand, June 1987) 47. 
Zealand's crisis of faith with the medical profession, particularly among women". ${ }^{6}$ While the Inquiry resulted in the creation of the Health and Disability Commissioner and the Code of Rights, apparent problems with self-regulation kept coming to light.

To illustrate, in 2000 the Gisborne Cervical Screening Inquiry ${ }^{7}$ considered the actions of pathologist Dr Michael Bottrill, who was found to have under-reported abnormal cervical smear test results. Counsel for affected women argued that the signs that Dr Bottrill was not competent were ignored and that this evidenced a "lack of 'internal morality' by some pathologists involved". ${ }^{8} \mathrm{Dr}$ Bottrill also faced a civil claim ${ }^{9}$ and it was reported that the medical profession had closed rank in his support by testifying that his errors were "within an acceptable margin for competent cytopathologists, when an Australian review indicated that this was not the case". ${ }^{10}$ Also in 2000, respected Christchurch doctor and mayoral hopeful Dr Morgan Fahey was convicted and imprisoned for sexually abusing female patients over a 30 -year period. Described by the media as a "sexual predator in a white coat", ${ }^{11}$ it was later discovered that other doctors "knew [of] or suspected" his unethical behaviour, ${ }^{12}$ and that some had been told of the abuse directly by patients but had "refused to believe it, telling the women that no one else would either". ${ }^{13}$

Public concern about the adequacy of the existing systems was, perhaps, understandable in the face of these highly publicised cases. Legislative change was therefore sought, in large part, to ensure that incompetent or bad practice could be identified early to enable a swift response and to minimise patient harm. ${ }^{14}$

6 Susan Rogers "Culling bad apples, blowing whistles and the Health Practitioners Competence Assurance Act 2003 (NZ)" (2004) 12 JLM 119 at 122.

7 AP Duffy, DK Barrett and MA Duggan Report of the Ministerial Inquiry into the Under-Reporting of Cervical Smear Abnormalities in the Gisborne (Ministry of Health, 2001).

8 Stuart Grieve and Antonia Fisher "Submissions to the Ministerial Inquiry" (12 September 2000) at [1.7].

9 Bottrill v A [2003] 2 NZLR 721 (PC).

10 Bronwyn Howell "Medical Misadventure and Accident Compensation in New Zealand: an Incentives-Based Analysis" (2004) 35 VUWLR 857 at 870 citing and commenting on Miriyana Alexander "Bottrill Cover-Up Astounds Lawyers: Doctors Closed Ranks" Sunday Star Times (New Zealand, 26 September 1999).

11 Alison Horwood and Jan Corbett "Fahey - sexual predator in a white coat" The New Zealand Herald (online ed, Auckland, 30 June 2000)

12 R Briant "Sexual Abuse in the Doctor-Patient Relationship" (paper presented to the Business Information in Action Second Annual Medical Law Conference, Wellington, November 2000) as cited in Rogers, above $n$ 6 , at 122 .

13 Rogers, above n 6, at 122.

14 Helen Cull Review of Processes Concerning Adverse Medical Events (Ministry of Health, March 2001). 


\section{B Competence and Competence Assurance}

The Act's principal purpose is "to protect the health and safety of the public by providing for mechanisms to ensure that health practitioners are competent and fit to practise their professions". 15 Because of the potential for ever-changing concepts of competence, and the range of professions captured by the Act, ${ }^{16}$ competence is not defined. ${ }^{17}$ However, the "required standard of competence" is defined as meaning "the standard of competence reasonably to be expected of a health practitioner practising within that health practitioner's scope of practice". ${ }^{18}$ Authorities are required to set standards of clinical and cultural competence; a practitioner's competence will be measured against these minimum requirements. ${ }^{19}$ Whether a practitioner meets the standard in any given profession is a matter for the relevant authority established under the Act. ${ }^{20}$ What is clear from the standards of competence that have been set across the various professions is that competence is something more than good clinical ("hands-on") ability. That is, a competent practitioner will also have, among other things, good verbal and written communication skills (for interacting with both patients and professional peers), skills relevant to the management and planning of health care, and an understanding of and compliance with legal and ethical obligations.

The mechanisms to achieve the Act's purpose include a requirement of competence for registration ${ }^{21}$ and the need to hold an annual practising certificate in order to practise the profession. ${ }^{22}$ Relevantly, a person may be registered within a scope of practice if he or she is fit for registration, holds a prescribed (or equivalent) qualification and is "competent to practise within the scope of practice". ${ }^{23}$ An authority may require an applicant for registration to take and pass an examination for the purpose of satisfying the authority that he or she is competent to practise in New

15 Health Practitioners Competence Assurance Act 2003, s 3(1).

16 The Act applies to 21 health professions regulated by 16 authorities. Regulated professions include anaesthetic technicians, chiropractors, dentists, dental therapists and technicians, dispensing opticians, medical practitioners, medical laboratory scientists and technicians, medical radiation technicians, midwives, nurses, occupational therapists, optometrists, osteopaths, pharmacists, podiatrists, psychologists, psychotherapists, and physiotherapists.

17 This was a deliberate drafting decision: see Health Practitioners Competence Assurance Bill 2002 (230-2) (select committee report) at 8 .

18 Health Practitioners Competence Assurance Act 2003, s 5(1).

19 Section 118(i).

20 D v Physiotherapy Board HC Wellington CIV 2006-485-1980, 15 October 2007 at [27] per MacKenzie J.

21 Health Practitioners Competence Assurance Act 2003, s 15(1)(c).

22 Section 7(2).

23 Section 15. Scope of practice describes the profession by reference to words, an area of science, tasks to be performed, or illnesses or conditions to be diagnosed or treated: see s 11 . 
Zealand. ${ }^{24}$ In turn, the practising certificate regime restricts the issue of a practising certificate where there are reasonable grounds for believing that "the practitioner has failed, at any time, to maintain the required standard of competence". ${ }^{25}$ An authority must not issue a practising certificate unless it is satisfied that the practitioner does indeed meet the required standard of competence. ${ }^{26}$ Conditions may be imposed on a practitioner's practice to assure the authority of their competence. ${ }^{27}$ Conditions may include practising under the supervision of another health practitioner, or preventing a practitioner from performing certain tasks. ${ }^{28}$

When a practitioner holds a current practising certificate, an authority has a discretion to review his or her competence. ${ }^{29}$ Competence reviews are a critical tool for assuring competence, and can involve onsite visits to observe a practitioner in practice, an assessment of cases and clinical records, and interviews with the practitioner and professional colleagues, among other things. While the form of a review is at each authority's discretion, ${ }^{30}$ a practice visit by a competence review committee followed by a written report to the authority is common.

Importantly, such reviews are not disciplinary, but are intended to be remedial and educative. The fundamental question for an authority in any review is whether the practitioner's practice of the profession meets the required standard of competence. ${ }^{31}$ If a practitioner is found to fall short of the required standard, then remedial orders must be made. ${ }^{32}$ Notably, an authority cannot cancel a practitioner's registration for incompetence; however it can put in place measures to restrict or prevent practice pending the completion of a competence review or until certain remedial orders have been fulfilled. ${ }^{33}$

\section{Notification of Competence Concerns}

A key trigger for undertaking a competence review is the receipt of a notification made under $\mathrm{s}$ 34 of the Act. ${ }^{34}$ Relevantly, s 34(1) provides:

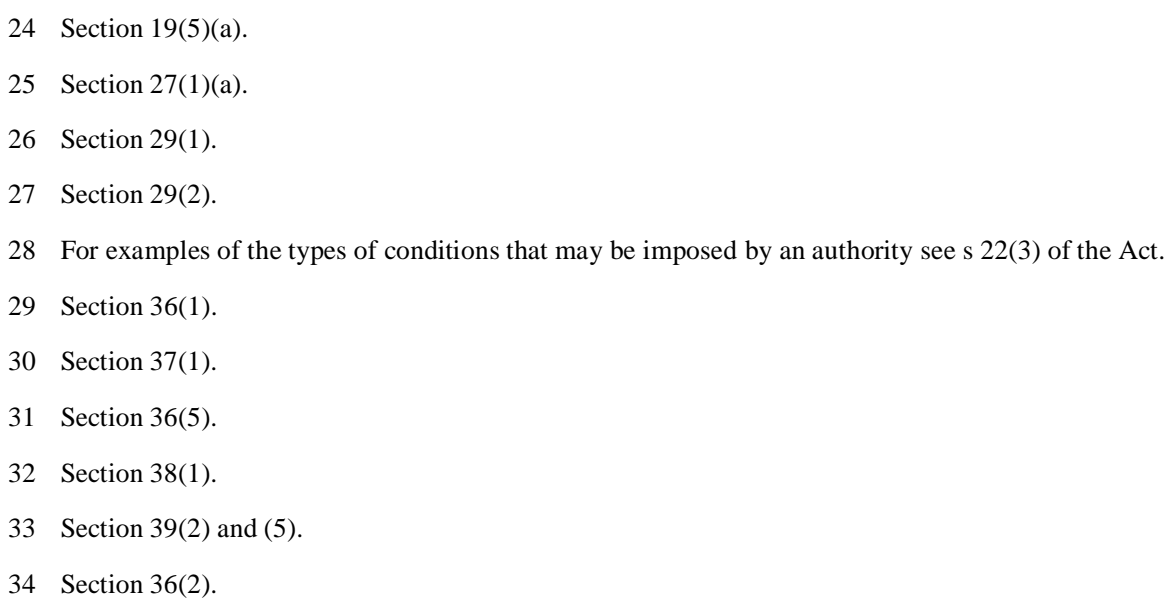


If a health practitioner (health practitioner $\mathbf{A}$ ) has reason to believe that another health practitioner

(health practitioner B) may pose a risk of harm to the public by practising below the required standard of competence, health practitioner A may give the Registrar of the authority that health practitioner B is registered with written notice of the reasons on which that belief is based.

As can be seen, a practitioner has a discretion whether or not to notify. A practitioner is not restricted only to making a notification about their professional peers; it is implicit that the Act permits notifications by a practitioner of one profession about a practitioner of another regulated profession. ${ }^{35}$ In deciding whether to notify, a practitioner is not required to form a definitive view that the other practitioner poses a risk of harm, or that that risk arises from incompetent practice. It is sufficient to have reason to believe that there may be questions about another practitioner's competence.

In contrast, s 34(2) creates a mandatory obligation on the Health and Disability Commissioner (HDC) to notify an authority of concerns on the same grounds. Similarly, under s 34(3) an employer of a health practitioner who resigns or is dismissed for reasons relating to competence must promptly notify the authority of the reasons for the resignation or dismissal. Importantly, no civil or disciplinary proceedings may be brought against a person making a notification, unless that person has acted in bad faith. ${ }^{36}$

\section{WHY DISCRETIONARY NOTIFICATION?}

When submissions were sought on the concepts to be included in a single piece of legislation for health regulation, one of the proposals was that practitioners would be required to report colleagues who were believed to be practising below an acceptable standard. ${ }^{37}$ In turn, the notifying practitioner would be protected from civil and criminal liability provided they had not acted in bad faith or without reasonable care. ${ }^{38}$

While 80 per cent of respondents commenting on the proposal "supported mandatory reporting of practitioners believed to be practising below an acceptable standard",39 there was strong opposition from the medical profession. ${ }^{40}$ Concerns were raised around the "subjective

35 Section 5 defines a "health practitioner" as a person who is, or is deemed to be, registered with an authority as a practitioner of a particular health profession. Section 34 applies to all health practitioners.

36 Section 34(4).

37 Ministry of Health Health Professionals' Competency Assurance Bill - Discussion Paper (September 2000).

38 At 16 .

39 Ministry of Health Summary of Submissions on the Health Professionals' Competency Assurance Bill Discussion Paper (February 2001) at 8.

40 Kathleen Jackson and Malcolm Parker "Full Steam Ahead on the SS 'External Regulator'? Mandatory Reporting, Professional Independence, Self-Regulation and Patient Harm" (2009) 17 JLM 29 at 31. 
interpretation" of the obligation, the risk of driving problems underground, vexatious reports and practitioner resistance leading to enforcement difficulties. ${ }^{41}$ The values of the profession, and reliance on the "internal morality of professional groups to govern themselves" also formed part of the debate. ${ }^{42}$

In 2001 the Cull review looked at existing processes around adverse medical events, including a proposed amendment to the Medical Practitioners Act 1995 to require mandatory reporting; it identified that practitioners were often aware of incompetent practice but did not report it. ${ }^{43}$ Cull concluded:44

... mandatory reporting would overcome the difficulties experienced by professionals in the health system to refer their concerns to the appropriate bodies and provide an added protection for public safety.

Notwithstanding the apparently overwhelming initial support for mandatory reporting, and Cull's conclusion which suggested that mandatory reporting might provide a protective shield for practitioners, the Bill was drafted without the requirement. ${ }^{45}$ The New Zealand Medical Association (NZMA), a strong opponent of mandatory notification of competence concerns, welcomed the decision not to require mandatory reporting, stating: ${ }^{46}$

This Bill is designed to improve the competence of health professionals. With the change away from mandatory reporting, the Bill will lead to safer environments for doctors and other health professionals to work in, and for patients.

Interestingly, much less attention focused on the proposal for mandatory reporting of concerns about a practitioner's mental or physical health as opposed to professional competence. While this paper does not address the reporting of practitioner health concerns, it is noted that s 45 of the Act creates a mandatory requirement for practitioners to notify an authority if there is reason to believe that another practitioner is unable to perform the functions required for the practice of the profession due to a mental or physical condition. ${ }^{47}$

41 Coates, above $\mathrm{n}$ 4, at 193.

42 New Zealand Medical Association "Submission to Health Select Committee on the Health Practitioners Competence Assurance Bill 2002" at 4

43 Cull, above n 14.

44 At 76.

45 Health Practitioners Competence Assurance Bill 2002 (230-1), cl 33(1).

46 "NZMA welcomes decision on Bill" (31 May 2002) Scoop News <www.scoop.co.nz>.

47 This obligation extends to persons in charge of an organisation providing health services, employers of health practitioners, and a Medical Officer of Health. 


\section{IS DISCRETIONARY NOTIFICATION REALLY SAFER FOR PATIENTS?}

It is not possible to confirm NZMA's assertion that discretionary reporting is safer for patients. No research has been conducted into the efficacy of discretionary reporting in New Zealand, and one difficulty must surely be that the number of concerns that go unreported is simply unknown. Similarly, there is no objective evidence that discretionary notification creates an environment in which competence concerns are more likely to be raised or managed locally, either within the workplace or as part of quality improvement initiatives.

There is also insufficient data to determine whether historical reluctance to report incompetent practice has changed. Prior to the introduction of the Act only 17 per cent of medical practitioners who underwent a competence review (a mechanism also available under the Medical Practitioners Act 1995) had been reported by their professional colleagues. ${ }^{48}$ No similar analysis of data has been undertaken for the various health professions regulated under the Act. However, one HDC report suggests that some practitioners remain reluctant to raise competence concerns. The case involved complaints against a medical practitioner regarding a number of failed sterilisation procedures. A colleague, Dr B, had informally expressed his "disquiet" about the practitioner's competence to the Medical Council, but he did not record his concerns in writing as requested by the Medical Council. ${ }^{49}$ The HDC commented, critically, that: "Dr B did not formally report his concerns until the evidence of incompetence was incontrovertible. By that stage it was too late." ${ }^{50}$ In making this comment the HDC referred to the professional responsibility to raise concerns, and the need for patients to have faith that poor performance will not be "swept under the carpet". ${ }^{51}$ Despite the criticism, no action was taken against Dr B. The case illustrates an example of where notification to an authority that would likely have been required under a mandatory regime was not made under the discretionary regime until patient harm had already occurred, an outcome that is surely inconsistent with the patient safety focus of the Act.

This raises questions about whether notifications required to be made by the HDC and employers provide an effective counterbalance to the discretion given to practitioners. Arguably not: the HDC will only become aware of a concern when there is a complaint or a notification from another agency, at which time the risk of harm has likely eventuated for the complainant. Likewise,

48 Ian St George "Doctors whose Competence has been Reviewed under the Medical Practitioners Act 1995" (2003) 116(1175) NZ Med J 1 as cited in Sumit Raniga and others "Attitudes of Hospital Medical Practitioners to the Mandatory Reporting of Professional Misconduct" (2005) 118(1227) NZ Med J 1 at 1.

49 Health and Disability Commissioner Dr Roman Hasil and Whanganui District Health Board 2005-2006: A Report by the Health and Disability Commissioner (February 2008) at 88.

50 At 89.

51 At 89. 
employers' obligations arise at the end of employment. Anecdotally, a number of employers are not aware of their obligations to report competence concerns. Others bind themselves with confidential agreements following the breakdown of the employment relationship and seek to rely on their terms to avoid reporting. In contrast to these after the fact notifications, practitioners working alongside their colleagues are well placed to recognise and report competence concerns early.

\section{MANDATORY NOTIFICATION IN AUSTRALIA}

In Australia, strong lobbying against mandatory reporting was unsuccessful. Since 2010 the Health Practitioner Regulation National Law Act 2009 has required practitioners to report "notifiable conduct", including where a practitioner has "placed the public at risk of harm because the practitioner has practised the profession in a way that constitutes a significant departure from accepted professional standards". ${ }^{2}$ Voluntary notifications may also be made for practice that is "below the standard reasonably expected". 53

Guidance issued by the Australian Health Practitioner Regulation Agency indicates that the threshold for mandatory reporting is high and that a "significant departure" is one which is serious and that "would be obvious to any reasonable practitioner". ${ }^{54}$ Despite the mandatory requirement to report there is no statutory penalty for failing to do so. ${ }^{55}$

Much like the justification advanced in New Zealand, the rationale for mandatory reporting was to ensure the safety of patients. Nevertheless, it has been contentious. Critics argued that mandatory reporting "fosters a culture of fear, deters help-seeking, and fuels professional rivalries and vexatious reporting". ${ }^{56}$ Debate continues around whether mandatory reporting is a reactive intrusion and an insult to the integrity of the profession. ${ }^{57}$

Recent research into mandatory notifications in Australia concluded that it was too soon to draw any conclusions on the effects of mandatory reporting, but that many of the concerns raised by

52 Health Practitioner Regulation National Law Act 2009 (Qld), s 140(d). All Australian states and territories have enacted the National Law.

53 Section 144(1)(b).

54 Australian Health Practitioner Regulation Agency and the National Boards "National Board guidelines for registered health practitioners: Guidelines for Mandatory Notifications" (March 2014) at 10.

55 At 13.

56 Marie Bismark and others "Mandatory reports of concerns about the health, performance and conduct of health practitioners" (2014) 201 Med J Aust 399 at 399

57 Malcolm Parker "Embracing the New Professionalism: Self-Regulation, Mandatory Reporting and their Discontents" (2011) 18 JLM 456 at 460. 
critics, and some of the benefits advanced by supporters, have not materialised. ${ }^{58}$ The authors observed that: ${ }^{59}$

... supporters of mandatory reporting who heralded it as a valuable new surveillance system may be concerned by the low rates of reporting. Part of the variation ... might reflect true differences in [the] incidence of notifiable events, but it is also likely that differences in awareness of reporting requirements and differences in notification behaviour contribute to the variation.

It is therefore unclear whether mandatory reporting has increased the likelihood of incompetent practice being notified, or whether patient safety has improved as a result. It is also too early to identify whether the legislative compulsion to notify, which removes any choice in the matter, offers either protection or comfort against the critics concerns.

\section{ETHICAL OBLIGATIONS}

One of the arguments raised against mandatory reporting in New Zealand (and Australia) was that ethical obligations already required practitioners to raise concerns about incompetent colleagues. Following the removal of the proposed mandatory reporting requirement in New Zealand practitioners were cautioned that ethical obligations were likely to impose a de facto legal duty to report colleagues based on the legal duties under the Code of Rights. ${ }^{60}$ However, for that argument to stand, codes of ethical conduct need to create sufficiently clear standards for notifying competence concerns and relevant agencies must enforce those obligations.

Ethical obligations imposed from within a professional body form part of the internal morality of a profession. ${ }^{61}$ The Hippocratic Oath is a good example; so too is the NZMA Code of Ethics. ${ }^{62}$ In addition to these internal controls of practitioner behaviour, the Act requires authorities to set standards of ethical conduct to be observed by practitioners. ${ }^{63}$ The Act regulates a number of professions and therefore there are a number of ethical codes. Some authorities have adopted or approved the codes developed by professional associations. For example, the Medical Council has endorsed the NZMA Code of Ethics for medical practitioners. ${ }^{64}$ Similarly, until recently oral health

58 Bismark, above n 56.

59 At 402

60 Jonathan Coates "Removal of the mandatory reporting provisions - only a Pyrrhic victory?" (2002) 115(1162) NZ Med J 1

61 Charlotte Paul "Internal and External Morality of Medicine: Lessons from New Zealand" (2000) 320 BMJ 499.

62 New Zealand Medical Association "Code of Ethics for the New Zealand Medical Profession" (2014).

63 Health Practitioners Competence Assurance Act 2003, s 118(i).

64 Ian St George (ed) Coles Medical Practice in New Zealand (12th ed, Medical Council of New Zealand, Wellington, 2013) at 6 . 
practitioners were advised that the Dental Council's (then) brief list of "Principles of Ethical Conduct for Oral Health Practitioners" should be read in conjunction with the Code of Ethics of the New Zealand Dental Association. ${ }^{65}$

While some codes of ethics create a mandatory obligation to report competence concerns, ${ }^{66}$ other codes (or guidance on codes) merely encourage reporting. ${ }^{67}$ This raises two issues. First, the lack of consistency undermines any argument that ethical obligations to report concerns are a sufficient counterbalance to the discretion to notify found in the Act. This inconsistency also creates a situation where a de facto legal duty to report concerns may apply to some practitioners regulated under the Act but not to others. Secondly, and significantly, there are real questions about the ability of an authority to set ethical obligations that exceed the statutory discretion to notify competence concerns. Put simply, it is unlikely to be lawful for an authority to set a mandatory ethical obligation to report competence concerns.

In any event, simply setting an ethical obligation to report concerns about incompetent colleagues is insufficient. It must be shown that those ethical standards are adhered to and enforced in order to maintain patient trust and to uphold patient rights. In terms of enforcement, the HDC, which investigates alleged breaches of patient rights, has never found a practitioner in breach for failing to report an incompetent colleague. Likewise, the Health Practitioners Disciplinary Tribunal (HPDT), which hears and determines disciplinary charges against practitioners, has not addressed the question in a disciplinary context. In the circumstances, the de facto legal duty is illusory.

\section{PRACTITIONER INTERESTS AND PATIENT SAFETY}

It is trite to observe that the care of the patient is the first concern in any therapeutic relationship. No practitioner would deny that upholding a patient's rights is also a basic obligation. Despite this, the factors that are said to impact on reporting behaviour fall into four indisputably practitionerfocused categories: ${ }^{6}$

... uncertainty or unfamiliarity regarding the legal requirement to report; fear of retaliation; lack of confidence that appropriate action would be taken; and loyalty to colleagues that supports a culture of "gaze aversion".

The extent to which New Zealand practitioners are aware of the discretionary reporting provisions of the Act is unclear. Even if there is an understanding that the Act creates a voluntary

65 In August 2015 the Dental Council introduced standalone ethical standards in its Standards Framework: see Dental Council Standards Framework for Oral Health Practitioners (2015).

66 For example Pharmacy Council Code of Ethics 2011 (January 2011) at cl 6.3, [15].

67 For example Chiropractic Board Code of Ethics (February 2013) at cl 3.3.7, [7]; and Medical Council What to do when you have concerns about a colleague (December 2010) at $\mathrm{cl} 20$.

68 Bismark, above n 56, at 402. 
reporting regime, the "culture of fear" is likely to have a chilling effect on exercising the discretion to notify. Anecdotally, many practitioners consider making a competence notification about a colleague to be "career suicide". The stark choice, particularly for junior practitioners, is between career advancement (and job security) and patient safety. In that respect, it can be readily assumed that it is safer for practitioners to have the choice not to notify bad practice. Thus, a consequence of discretionary notification is that a practitioner may choose not to notify in order to protect themselves, even after observing practice that may harm a patient. This choice goes against what the Act sought to address.

From a patient perspective, substandard practice may not be recognised until harm occurs. At that point, while there is a right to complain, ${ }^{69}$ and the possibility of cover for a treatment injury, ${ }^{70}$ there may be questions about how the substandard practice went unchecked and why others did not intervene to prevent the harm. Such questions have the potential to undermine public trust and confidence in health practitioners. The risk of a loss of trust and confidence is increased if it is accepted that practitioners often know which of their colleagues is practising below an acceptable standard.

Identifying and reporting bad practice goes hand in hand with protecting patient safety. If practitioners accept that patient safety comes first at all times then their own interests are, theoretically at least, irrelevant. That said, can practitioners protect themselves and patient safety by using different methods to report their concerns? Two possible reporting methods, and the protection they may provide to both practitioner and patient interests, are considered below.

\section{A Protected Quality Assurance Activities}

The Act protects practitioner confidentiality with respect to declared quality assurance activities (QAAs) that have been approved for a particular organisation. ${ }^{71}$ QAAs are intended to improve the practice or competence of practitioners by assessing and evaluating circumstances that may affect the quality of health services. ${ }^{72}$ Practitioners participating in a QAA can be assured that, except in limited circumstances, information will not be disclosed outside the organisation and cannot be used against them for disciplinary purposes. ${ }^{73}$

69 Code of Rights, above n 1, right 10.

70 Accident Compensation Act 2001, s 32

71 Health Practitioners Competence Assurance Act 2003, s 53(1). A QAA must have a sponsor, meaning a person or association of persons, under whose initiative and guidance the QAA is undertaken. Broadly speaking, employer organisations (such as hospitals and District Health Boards) and professional associations have QAA processes in place: see for example Health Practitioners (Quality Assurance Activity - Auckland DHB) Notice 2013.

72 Health Practitioners Competence Assurance Act 2003, ss 52-63.

73 Sections 59 and 62. 
However, the disclosure of competence concerns within the protection of a QAA process means that an authority will not be made aware of the concern. It is the authority that has a statutory power to assess and remediate practitioner competence; its decisions about managing competence concerns are made with the principal purpose of protecting the health and safety of the public at front of mind. If competence concerns are not appropriately addressed by an organisation as part of a QAA process, there could well be ongoing safety implications for patients. Moreover, any later notification to an authority will not disclose the earlier (confidential) concerns or the efforts to address the deficiencies in the practitioner's practice, potentially minimising the extent of the incompetent practice and possibly affecting the authority's response to the notification. Thus, while QAAs protect the practitioner it is less clear that they act to protect the public from incompetent practice in the long term.

\section{B The Protected Disclosures Act 2000}

The Protected Disclosures Act 2000 (PDA) protects the identity of a whistle-blower who discloses serious wrongdoing within an organisation. Serious wrongdoing includes "an act, omission, or course of conduct that constitutes a serious risk to public health or public safety" and "an act, omission, or course of conduct by a public official that is ...grossly negligent, or that constitutes gross mismanagement". ${ }^{74}$ The PDA's protection extends to immunity from criminal, civil or disciplinary proceedings relating to the disclosure. ${ }^{75}$ In principle, the PDA could be used by a practitioner to raise concerns about seriously incompetent practice, or the failure of an organisation to address incompetent practice, without jeopardising career prospects.

The PDA requires that the disclosure is made in accordance with internal procedures. Invariably, this requires disclosure within the organisation in the first instance. A disclosure may only be made directly to an "appropriate authority" if the organisation does not take adequate steps to respond to the disclosure, where the head of the organisation is involved in the wrongdoing or where urgency is required. ${ }^{76}$ An appropriate authority includes the HDC and "the head of every public sector organisation". ${ }^{77}$ An authority established under the Act would likely be regarded as an appropriate authority for the purpose of the PDA.

Although the PDA provides protection for a whistle-blower practitioner, there remains a genuine risk that the whistle-blower will be known or identifiable within the organisation and will suffer covert discrimination as a result of the disclosure. Retaliatory action linked to the disclosure, including dismissal, may amount to a personal grievance but that protection would no doubt be cold

\footnotetext{
74 Section 3

75 Section 18.

76 Section 9

77 Section 3.
} 
comfort for a practitioner. ${ }^{78}$ Uncertainty about the true scope of the protection offered by the PDA may influence a practitioner's decision about disclosure. As with discretionary notification under the Act, a decision not to disclose serious wrongdoing may be made to protect against the implications for that practitioner, regardless of the risk to the public. The result is that the PDA might not be used by practitioners to report incompetent practice even when it is in the interests of patient safety to do so.

\section{WHAT NEXT? OPTIONS FOR IMPROVEMENT OR CHANGE}

Having considered the discretionary regime, ethical obligations, and the factors that are likely to inhibit discretionary notification the next question is what can be done to ensure that practitioners report their concerns about bad practice. The following options are proposed.

\section{A Research}

New Zealand-based research into trends and behaviour around reporting of incompetent practice is required. To date, no comprehensive research into competence notifications across the regulated professions has been undertaken. Data on competence notifications and the sources of such notifications are available in the annual reports of the authorities, but requires compilation and analysis to determine the number of notifications made by practitioners compared to other sources.

Analysis of this data will not identify incompetent practice that has gone unreported or the reasons for such lack of reporting. A survey of practitioners across the regulated professions could inquire into circumstances where incompetent practice was not reported, circumstances where incompetent practice was reported through other means (for example through QAAs or under the PDA) and the outcome of such reports, the perceived impediments to making notifications to authorities, and the extent to which patient safety is a factor in deciding whether or not to make a notification. The scope of practitioners' current understanding of legal and ethical obligations regarding incompetent colleagues can also form part of the survey. By offering anonymity, save for the participant's profession and years of practice, such a survey could provide a frank picture of reporting behaviour in New Zealand, and may assist to determine whether there is indeed a reluctance to report voluntarily and how that might be fixed.

A survey of practitioners might also be an opportunity to re-examine the various professions' views on mandatory reporting. While the medical profession, through the NZMA, has long been an opponent of mandatory reporting it may be that this view is not shared either by individual practitioners or across the 21 regulated professions. This can only be determined by seeking the views of all professions. If the medical profession's view is a minority view then it is questionable

78 Section 17 provides that where an employee who makes a protected disclosure under that Act claims to have suffered retaliatory action (including dismissal) from his or her employer or former employer the employee may have a personal grievance. 
whether the voice of one (albeit important) profession should take priority over other professions on such an important factor for protecting patient safety.

\section{B Education}

It is likely that many practitioners are unfamiliar with the steps that can, or should, be taken when confronted with substandard practice. There is a risk that leaving a junior practitioner to learn about when or whether to report competence concerns by following the example set by senior colleagues could entrench non-reporting behaviour. Educating practitioners about their legal and ethical obligations is critical to practitioners meeting their duty to uphold patient rights as set out in the Code of Rights. ${ }^{79}$

The need for education to address the legal and ethical obligations relevant to practice, including patient rights and the management and notification of competence concerns, can be reinforced by authorities when they set the prescribed qualifications for registration. ${ }^{80}$ Authorities can choose to designate only those qualifications that specifically address professional responsibilities alongside the broader clinical requirements for practice. Those education providers who do not address such matters would need to adjust their programme to ensure that their students have a qualification that is relevant for registration in their chosen profession. Authorities are also able to set competence programmes or recertification programmes for practitioners. ${ }^{81}$ Successful completion of such a programme, usually on an annual basis, is often used by authorities to demonstrate a practitioner's competence for the purpose of issuing a practising certificate. These programmes can specify a course of instruction and/or a pass in stated assessment as a necessary component. ${ }^{82}$ Accordingly, once registered, education and assessment about legal and ethical obligations can be set as an express requirement for practitioners as part of their ongoing professional development during the course of their careers.

More broadly, authorities have a role in educating practitioners about competence notifications and competence reviews. It is important that practitioners understand how a notification is likely to be treated, the possible outcomes of notification, what a competence review involves and that competence reviews are not disciplinary processes. It is also important that practitioners understand that, if they notify in good faith, they have immunity from prosecution. ${ }^{83}$ While many authorities have information about competence reviews on their websites, regular and more targeted

79 It is also relevant to meeting the principal purpose of the Act, which is to protect the health and safety of the public: see s 3 .

80 Section 12.

81 Sections 40 and 41.

82 Sections 40(1)(a) and (b), and 41(1)(a) and (c).

83 Section 34(4). 
information sent directly to practitioners may be a more effective way of ensuring that individual practitioners understand the importance of raising concerns about incompetent practice and the implications of doing so.

\section{Guidelines for Discretionary Notification}

The threshold for exercising the discretion to notify requires a practitioner to consider two factors: "risk of harm to the public" and "required standard of competence". ${ }^{84}$ While "public" may reasonably be read as including any patient or possible patient of a particular practitioner, "risk of harm" is not defined by the Act and the phrase has not, to date, been interpreted by the courts. The required standard of competence is a defined term that has been the subject of judicial consideration, but it cannot be assumed that practitioners will know what is meant by this phrase. Guidance as to when the threshold for reporting may be met would assist practitioners.

In 2010 the Health Regulatory Authorities of New Zealand (HRANZ), an informal group of the authorities established under the Act, issued a joint guideline with District Health Boards (DHBs) called the Agreed Guidelines for Competency Referrals. ${ }^{85}$ The Guidelines do not directly address the required standard of competence, but do state that a risk of harm may be indicated by "a pattern of practice over a period of time that suggests the practitioner's practice may not meet the required standards of competence". ${ }^{86}$ However, the Guidelines are expressly intended for DHBs. Many practitioners may not consider the Guidelines applicable to them, and in any event may not be able to readily locate them. Although some authorities have developed their own criteria for determining whether a risk of harm may exist, ${ }^{87}$ consistency as to the meaning of "threshold" phrases is preferable to ensure consistency of reporting across the professions. HRANZ is an appropriate group to issue guidance as to when the threshold for notification may be met. A useful starting point would be the guidelines developed by the Australian Health Practitioner Regulation Agency for mandatory notification in that country. Those guidelines explain in simple terms to whom they apply, what is meant by the statutory tests, and sets out a decision-making tree with the matters to take into account when considering making a notification. ${ }^{88}$

84 Section 34(1).

85 Health Regulatory Authorities of New Zealand HRANZ/DHB Agreed Guidelines for Competency Referrals (July 2010).

86 At 11 .

87 For example the Medical Council states that a risk of harm may be indicated by "a single incident that demonstrates a significant departure from accepted standards of medical practice" or "recognised poor performance where local interventions have failed": see Medical Council of New Zealand "Definitions of risk of harm and risk of serious harm" (August 2004) at 1.

88 Australian Health Practitioner Regulation Agency and the National Boards, above n 54. 


\section{Enforcement}

If reporting competence concerns is to be taken seriously by practitioners it may be necessary for egregious failures to report incompetent practice to have consequences. While notification under the Act is discretionary, for some professions there is an overarching ethical obligation set by the relevant professional body that requires competence concerns to be reported. As noted above, the Code of Rights imposes a duty on practitioners to provide services that comply with legal, professional and ethical standards. On the face of it, if a practitioner who is subject to an ethical obligation to notify incompetent practice does not report incompetent practice he or she will be in breach the Code of Rights. The HDC, as the watchdog for health consumers, has a responsibility to ensure that practitioners meet their professional and ethical responsibilities when providing services. It would be unfortunate indeed if health consumers had to wait for another high profile medical scandal before real steps are taken to uphold a patient's rights to services that meet a profession's own ethical expectations.

Authorities also have a role to play. While there may be questions about an authority's ability to set a mandatory ethical obligation to report competence concerns, the immunity from civil or disciplinary proceedings only applies when a discretionary notification has been made. What happens when a discretionary notification is not made and it is said that a practitioner knew or ought to have known that a colleague was incompetent and that it was inappropriate not to have taken steps to raise the concern or to prevent the colleague from practising? Under s 68(3) of the Act an authority has a discretion to refer questions about the appropriateness of a practitioner's conduct to a professional conduct committee (PCC). Unlike the authority itself, a PCC has a statutory power to lay disciplinary charges before the HPDT. ${ }^{89}$ Relevantly, a practitioner may be guilty of professional misconduct for "any act or omission that, in the judgement of the Tribunal, has brought or was likely to bring discredit to the profession". ${ }^{90}$ The HPDT, which sets and enforces professional standards, has long held that to bring discredit is to bring harm to the "reputation and good standing" of the profession in the eyes of reasonable members of the public. ${ }^{91}$ It is not inconceivable that, on the right facts, a PCC might test the scope of professional misconduct with respect to a practitioner's failure to raise concerns about an incompetent colleague.

89 Health Practitioners Competence Assurance Act 2003, s 80(3)(b). A PCC can also recommend that an authority review a practitioner's competence.

90 Section 100(1)(b)

91 An endorsement of the statement made by Gendall J in Collie v Nursing Council of New Zealand [2001] NZAR 74 (HC) at [28]. 


\section{E Legislative Change - Mandatory Notification}

Two reviews of the Act have not resulted in any recommended changes to the discretionary reporting provisions. ${ }^{92}$ This may be because discretionary reporting is accepted as an appropriate (or pragmatic) legal response. Alternatively, it may indicate a lack of enthusiasm by the legislature to re-engage in the debate. Nevertheless, mandatory reporting could become necessary if the public loses confidence in the various professions' preparedness to report incompetent practice under a discretionary regime. Subject to the outcome of any relevant research, including further proposed research in Australia into the effects of the mandatory reporting regime in that jurisdiction, and the impact (if any) of the measures suggested above, introducing mandatory reporting should be reconsidered.

\section{Mandatory reporting requirements}

The success of a mandatory reporting regime will very likely depend on two key and interrelated factors: the threshold for reporting should be high and the scope of the obligation to report should be clear. Put another way, if practitioners are to be required to report their allegedly incompetent colleagues, they should only be required to do so where the incompetent practice obviously and objectively poses a risk of serious harm to patients. For example, s 34(1) could be amended as follows:

If a health practitioner (health practitioner A) has reasonable grounds for believing that another health practitioner (health practitioner B) poses a risk of serious harm to the public by practising in a way that is a significant departure from the required standard of competence, health practitioner A must give the Registrar of the authority that health practitioner B is registered notice of the circumstances and/or reasons giving rise to that belief (amendments underlined).

The proposed amendments would create a clearer objective standard for belief, in contrast to the current "reason to believe" which may be regarded as having at least some subjective element. An objective standard ensures that a practitioner is not influenced by his or her personal views when considering making a notification, perhaps ensuring that patient safety is paramount. In addition, amendment of the words "may pose a risk of harm" to "poses a risk of serious harm" means that a practitioner need only notify if there is an objective basis for believing that practitioner B does indeed pose a risk, and that the risk posed is serious. For clarity, "serious harm" ought to be defined

92 The Health Practitioners Competence Assurance Act 2003 was reviewed in 2007 and 2012. In 2007 the New Zealand Medical Association stated that it "has always been opposed to mandatory reporting in respect of competence issues .... Our concern is that mandatory reporting of competence issues is likely to result in the issue being avoided, thus having the opposite effect to what is intended": New Zealand Medical Association "Review of the Health Practitioners Competence Assurance Act (HPCA) - Key Issues" (submission to Ministry of Health, 17 December 2007). 
by the Act and may include, without limitation, actual or potential harm to the life or health of a patient. ${ }^{93}$

The threshold for mandatory notification in Australia involves a "significant departure" from accepted standards. This threshold should be adopted in New Zealand. As in Australia, it can be contended that a significant departure is one which is serious and one which would be readily identifiable to any reasonable practitioner. Certainly, a significant departure is something more than a minor deviation from accepted standards of practice. Issuing guidance along the lines seen in Australia would assist practitioners to determine the significant departure threshold for reporting. ${ }^{94}$ Guidelines, which have the advantage of being relatively easy to amend if required, can also clarify that a single serious incident or progressively serious lapses in practice over a period of time would meet the threshold for reporting provided that there is also serious harm.

The proposal does not alter the statutory language of the "required standard of competence", which is already a defined term that has been the subject of judicial comment. Nevertheless, consideration should be given to amending the definition of the "required standard of competence" by adding that the relevant standard is that which is set by the authority under s 118(i). This would direct practitioners who are considering making a mandatory notification to consider the current competence standards for the relevant authority.

As currently worded, s 34(1) requires a practitioner to give written notice of competence concerns. While written notice is commensurate with the seriousness of the notification, it also creates a level of formality that might not be necessary. A practitioner should be permitted to make a notification either in writing (including by email) or verbally. With verbal notifications it would also be crucial that the authority makes a written record of the verbal notification without delay; this could be a statutory requirement in those circumstances. ${ }^{95}$ A verbal notification would also require an authority and its staff to ensure that they obtain adequate information to identify the practitioner making the notification and the basis on which the notification has been made. Knowing the identity of the practitioner making the notification is necessary to protect against vexatious reports. It is also consistent with the broad principles of natural justice of the practitioner who is the subject of the notification to be aware who has made the notification and the reasons for it. If the practitioner making the notification wishes to protect his or her identity that will ultimately become a question

93 HRANZ/DHB Agreed Guidelines for Competency Referrals, above n 85, at 12 states that a risk of serious harm may be indicated when "a patient may be seriously harmed; or the practitioner may pose a threat to more than one patient and as such the harm is collectively considered serious". Note that a "risk of serious harm" is relevant under s 39 of the Health Practitioners Competence Assurance Act 2003 when considering interim orders pending the outcome of a competence review or completion of certain remedial orders.

94 It is suggested that the Health Regulatory Authorities of New Zealand would be an appropriate body to publish these guidelines.

95 See for example Health Practitioner Regulation National Law Act 2009 (Qld), s 146(3). 
for the authority having regard to the principles of access to and disclosure of personal information under the Privacy Act 1993. ${ }^{96}$

Like the current regime, practitioners who make a notification in good faith (whether mandatory or voluntary) should have immunity from civil or disciplinary proceedings. Protection could also be extended to any retaliatory action by an employer by adopting the personal grievance provisions similar to s 17 of the PDA. While this protection would not prevent retaliation, it would reinforce that reprisal for meeting an important statutory obligation is wholly unacceptable. Alongside these statutory protections, authorities should ask themselves what sort of behaviour they expect to be observed with respect to those practitioners who make mandatory notifications. There is room for ethical obligations to reflect an expectation that practitioners are to be supported in meeting their legal obligations, and not to be treated discourteously or disrespectfully for doing so. In addition, the existence of a mandatory reporting obligation would permit authorities to set ethical obligations to reinforce the need to bring incompetent practice to the attention of the relevant regulatory authority.

Finally, the mandatory obligation to report should be extended to capture persons in charge of organisations that provide health services and employers of health practitioners. ${ }^{97}$ In this way, the obligation to report is shared within the practice environment. This has two possible advantages. First, practitioners will not feel that they are singularly responsible for identifying and reporting competence concerns. Secondly, it might have an unforeseen but desirable effect of genuinely encouraging early local (employer and organisation) interventions before the threshold for notification is met. This may well address any perceived risk that mandatory reporting will drive problems underground. The motivation for early management of low level competence concerns might be more pronounced in a mandatory reporting regime than with discretionary notification.

However the legislative change is framed, mandatory reporting would signal a shift in focus from protecting practitioner interests to protecting patient safety. The way in which the regulated professions respond to any legislative change will be as important, if not more so, than the regulatory response of the authorities. It must be recognised that one final aspect relevant to the success or otherwise of a mandatory reporting regime is more difficult to achieve through legislative change: that is, practitioner buy-in. It is hoped that this can be achieved through setting the reporting standard high, providing appropriate and accessible guidance on the threshold for mandatory reporting, and encouraging professional associations to focus their efforts in promoting early management and support for struggling practitioners and endorsing mandatory reporting in circumstances where it can reasonably be said that practitioner incompetence compromises patient

96 Authorities are not subject to the Official Information Act 1982.

97 See s 45 of the Health Practitioners Competence Assurance Act 2003 which extends the mandatory reporting of health concerns to these individuals. Note also that by extending the notification to employers of practitioners this would cover the period of a practitioner's employment and not solely circumstances where he or she resigns or is dismissed for reasons relating to competence. 
safety. In the words of one Australian commentator, professional endorsement of mandatory reporting should be encouraged: ${ }^{98}$

$\ldots$ in recognition of the profession's past failings and the close alignment between the requirements of mandatory reporting and the profession's assertions about its ethical obligations to take responsibility for members who practise at inadequate standards.

A statutory requirement to notify an authority of competence concerns would, for some professions, replicate the ethical obligations that have existed for a number of years. One argument in favour of mandatory reporting must be that it goes no further that most professions already require of themselves. If mandatory reporting demands no more than the professions have expected of themselves then there is nothing to fear and plenty to gain in terms of patient safety and upholding patient rights.

\section{Retention of discretionary notification}

For completeness, the discretionary notification regime should be retained for reporting incompetent practice that does not meet the threshold for mandatory notification. It is appropriate that those practitioners who have legitimate concerns about another practitioner's competence to practise and who act in good faith in raising those concerns are given statutory immunity from civil or disciplinary action when making a voluntary notification.

Finally, the Act is silent on whether persons other than practitioners, the HDC and employers can notify an authority of competence concerns. This may be because it was assumed that a lay person is unable to identify when a practitioner is or is not meeting the required standard of competence. But whether that assessment is able to be made by that person is irrelevant. It is for the authority to determine the validity of the concern and its response to the notification. An unregulated health professional, for example a health care assistant working alongside a regulated practitioner, or a receptionist, is as well placed as another practitioner to identify practice that may pose a risk of harm to patients. Similarly, a patient or a patient's family may have valid concerns about the appropriateness of the care that is provided. While there is nothing to prevent other people from notifying an authority of competence concerns, and perhaps those concerns make their way to the HDC in the first instance, it should be clarified that there is nothing to prevent voluntary notifications being made by any other person.

\section{CONCLUSION}

Early recognition, early notification and a prompt response to competence concerns are consistent with protecting public health and safety. The absence of a statutory obligation for practitioners to report competence concerns creates a risk that problems will go unreported and that patients may be exposed to harm. Mandatory reporting obligations for the HDC and employers may

98 Malcolm Parker, above n 57, at 465. 
come too late to avoid harm, and ethical obligations do not provide a safety net as they are inconsistent and have not, in any event, been enforced. It is therefore debatable whether discretionary reporting is good enough to uphold patient rights and to meet the purpose of the Act.

A number of steps are required to test the appropriateness of discretionary reporting, including New Zealand-based research into the sources of competence notifications and reporting behaviour across all regulated professions. Subject to this research, education about patient rights, patient safety and the management and reporting of competence concerns is required, together with consistent guidance on the threshold for discretionary reporting and enforcement of existing ethical and professional obligations by appropriate agencies in appropriate cases.

If the suggested improvements are ineffective to increase discretionary notifications of competence concerns, then it may be that legislative change to require mandatory reporting in certain circumstances will become necessary. In other words, if practitioners are not prepared to voluntarily raise competence concerns then it is almost inevitable that this requirement will be imposed upon them. From a patient-centric perspective, having regard both to the Code of Rights and the principal purpose of the Act, mandatory reporting has the potential to reinforce the central importance of patient safety and patient rights in the provision of health services. 